\title{
Concept for an International Fieldcourse in Sustainable Mining under Arctic Conditions
}

\author{
Esther Takaluoma $^{1}$, Risto Oikari ${ }^{1}$ \\ ${ }^{1}$ Kajaani University of Applied Sciences \\ Kuntokatu 1, Kajaani, Finland \\ esther.takaluoma@kamk.fi; risto.oikari@kamk.fi
}

\begin{abstract}
In this paper, a successful concept for the organization and implementation of an international course is described. Kajaani University of Applied Sciences is responsible the main area in Sustainable Mining and Circular Economy, while the partners supplement the teaching with background in Geology, and working in Arctic Areas. Stakeholders and policymakers were invited to share their point of view. The course concept is based on theoretical and hands-on courses, knowledge transfer, and industry participation. The concept was piloted in 2019 and was updated in 2020 and 2021 accommodating to the global pandemic and travel restrictions, with the inclusion of virtual laboratory exercises and virtual excursions.
\end{abstract}

Keywords: Sustainable Mining, Education, Arctic, Circular Economy, Course pilot

\section{Introduction}

The European Union has set an ambitious goal, that by 2030, $40 \%$ of all sold cars shall be electric vehicles (EVs). This means, that by 2030, there should be 220 miljon EVs in Europea. The production of battery powered cars stresses the supply chain of already critical raw materials such as cobalt, lithium, and nickel. In fact, it has been estimated, that the cobalt demand will exceed the supply. [1] Finland is currently the only country in Europea with an active cobalt mine, and several cobalt mineralizations are being investigated. According to the Canadian Fraser Institute in 2020, Finland is considered the worlds second most interesting country in terms of the Investment Attractiveness Index, which combines the Mineral Potential Index and the Policy Perception Index, after Australia. [2] Finland has gained an excellent international reputation for innovations in mining technology, beneficiation of complex ores, and the application of sustainable mining in circular economy in the mining sector. Strict environmental and mining laws (currently being reassessed) and the sensitive arctic environment, in coordination with public scrutiny, pushes innovative actions along the whole mineral value chain to reduce the environmental impact and the contamination of mining areas. Because over $85 \%$ of Finnish surface water is potable, research about mine water purification techniques to further reduce purging of potential hazardous material is vivid, and one of the focusses at the R\&D unit at Kajaani University of Applied Sciences.

To enable the switch to electric mobility, mining of critical raw materials will increase. The arctic area in Canada, Finland, and Russia, are expected to board large quantities of mineable mineralizations, of international interest. The need for sustainable mining in these environments is obvious, and Finland has a well established knowledge-base regarding mining under arctic conditions, resulting a great potential for educational export to the interested. In here, a course concept for Sustainable Mining under Arctic Conditions is described, which has been piloted for three times in 2019 and 2020. It is of equal importance to assess possibilities to recreate excursion and laboratory work experiences in remote teaching courses.

\section{Sustainable Mining under Arctic Conditions}

A four week course with the topic Sustainable Mining under Arctic Conditions was piloted in 2019 by Kajaani University of Applied Science (KAMK) and partners, according to Table 1, and switched to remote teaching during 2020. The main structure of the courses can be divided into orientation task before intensive period (3 ECTS), main teaching block in Finland (10 ECTS), and reporting and/or exam (2 ECTS). The focus was on innovative methods to incorporate sustainability and circular economy into the mining value chain, discussing state-of-the-art mine water 
treatment methods, zero-waste, and RO-brine stabilization, incorporating research conducted at the partner universities. Also end of mine methods from tailinds stabilization and remediation towards reuse strategy of underground mines, e.g. for the production of renewable energy as hydroponic energy storage. Groupwork each afternoon discussed and deepened the subjects, and the students were asked to integrate the new knowledge into the mining background of their own countries.

The last topic is the application of modern exploration and mining into the context of arctic surroundings, with all the challenges and risks associated. The overview starts from infrastructure and transportation to associated risk, food supplies and cold protection.

Table 1: Partners involced in Sustainable Mining in Arctic Area courses and respective expertise.

\begin{tabular}{|l|l|l|l|l|}
\hline Partner & $\begin{array}{l}\text { Kajaani University of } \\
\text { Applied Sciences }\end{array}$ & $\begin{array}{l}\text { Lapland University of } \\
\text { Applied Sciences (2019) }\end{array}$ & $\begin{array}{l}\text { University of Oulu Hangasojan Kulta Oy } \\
\mathbf{( 2 0 2 0 )}\end{array}$ \\
\hline Expertise & $\begin{array}{l}\text { Sustainable Mining, } \\
\text { Circular economy, } \\
\text { Water treatment, } \\
\text { Tailings remediation }\end{array}$ & $\begin{array}{l}\text { Modern beneficiation, } \\
\text { hands-on exercises }\end{array}$ & $\begin{array}{l}\text { Oulu Mining School, } \\
\text { Sustainable } \\
\text { Beneficiation, Geology, } \\
\text { Pilot plant, }\end{array}$ & $\begin{array}{l}\text { Mining and exploration } \\
\text { in Arctic Area, Risk } \\
\text { Assement, Geology, } \\
\text { Gold prospecting }\end{array}$ \\
\hline Personal & $\begin{array}{l}\text { Principle lecturer, } \\
\text { lecturer, and senior } \\
\text { researcher }\end{array}$ & Lecturer & $\begin{array}{l}\text { Professors and senior } \\
\text { researcher }\end{array}$ & $\begin{array}{l}\text { Senior } \\
\text { lecturer/geologist }\end{array}$ \\
\hline Company network & Terrafame Oy & All mines in Lapland & Kemi mine & $\begin{array}{l}\text { All mines in Lapland, } \\
\text { gold fields }\end{array}$ \\
\hline \% 2019 & 40 & 30 & & 30 \\
\hline \% 2020 & 40 & & 40 & 20 \\
\hline
\end{tabular}

': Approximate distribution of teaching responsibilities among the partner.

\subsection{Mining under Arctic Conditions}

"The Arctic still contains endless mineral reserves, however the exploration is difficult, and the exploitation even more difficult. Yet the challenges can be solved, and Finnish know-how has a lot of solutions to give for these problems." Senior Geologist, Antti Peronius.

The course concept has a special focus on the risks and problems arising in working, living and exploration in the Arctic ( Figure 1). The students learned how the cold affects maschinery, health, and how to stay warm. Academic topics included the geology of Arctic areas, glacial movements, and resource estimations. Additional, the extraordinary effects of the polar night, and the need of leadership under strenuous conditions. During group work the students were encouraged to plan an exploration trip to the Russian Arctic and to discuss the risks associated with the endeavour. 


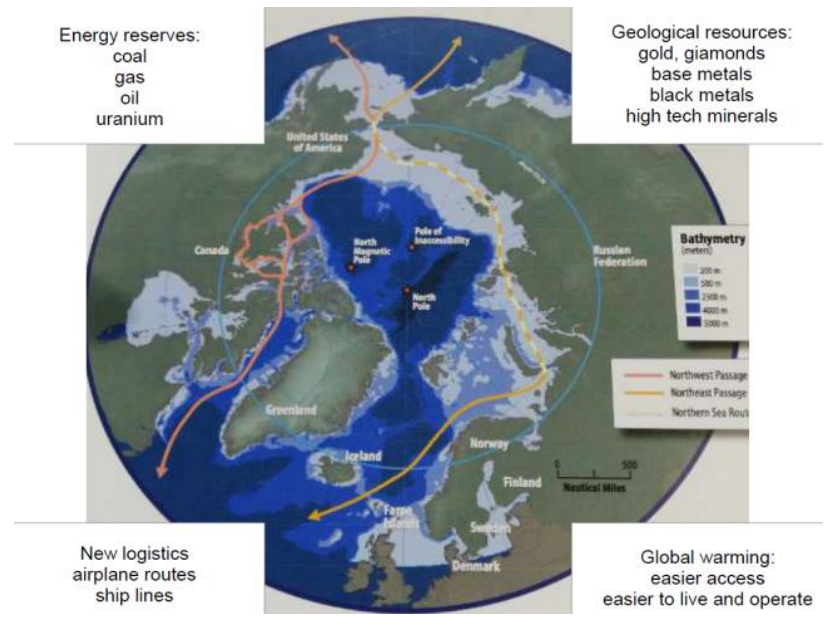

Figure 1: Discussion of Arctic resources, A. Peronius.

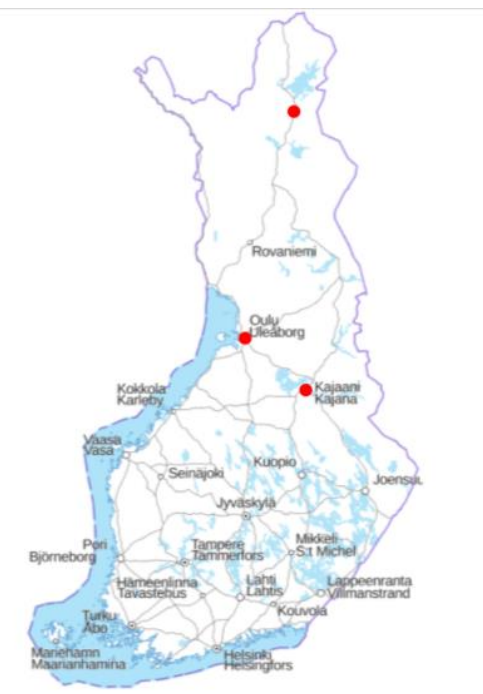

Figure 2: Map of Finland indicating the position of partners (GTK).

\subsection{Summerschool August 2019}

The Summerschool 2019 could be held as planned including an intensive study period in Finland. Most students came from China, from the University of Science and Technology in Beijing (USTB) and from the Shandong University ofTechnology (SDUT). In addition, there was a single student from the University of Chongqing, from Akita University (Japan), University of Kentucky (USA), and University of Western Australia (Australia). The stay in Finland was divided into three parts, two weeks in Kajaani with lectures, mine visits, and laboratory work, followed by a more relaxed period about Finnish geology and Arctic living at the Saariselkä area in North Lapland, and a final week in Rovaniemi and Kemi at the University of Applied Science Lapland.

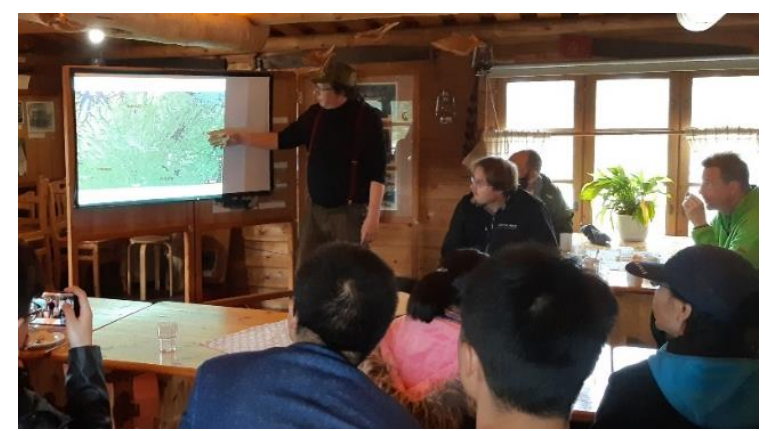

Fig. 1: Senior geologist Antti Peronius, giving a lecture about glacial movement, in a typical cottage during fieldtrip to Lapland.

Laboratory exercises at Kajaani University of Applied Sciences included the preparation of geopolymers, stabilization of tailings, modern beneficiation, and accelerated leaching procedures, in groups of six. The students learned about the utilization of certain tailings as a precursor for geopolymers, and the about the utilization of geopolymers in wastewater treatment and as concrete substitute. At the end, each student had their own geopolymer sample. 
The stakeholder participation in the courses are compiled in Table 2.

Table 2: Examples of stakeholder involvement in Arctic Mines courses.

\begin{tabular}{|l|l|}
\hline Stakeholder & role or discussion \\
\hline Local mines & Excursion, expert lectures, “Sustainability with us" lectures \\
\hline Mining Finland & local mining industry lobby, role discussion \\
\hline Sustainable Mining network & introduction to network's role \\
\hline TUKES & Mining authority, role \\
\hline Centre of Economic Development & Mining supervision, role \\
\hline Finnish Mining Association & Miner's Association, role, EIA \\
\hline
\end{tabular}

The week in Saariselkä was structured in morning lecture, daily field activities and reporting, and evening program, and had therefore the biggest impact in cultural understanding.

\subsection{Feedback 2019}

Feedback from all participants was requested before transfer of credits. Overall the summerschool was a great success for all students, however, a four week period was considered too long. All students especially enjoyed the excursions and hands-on laboratory work. Lecturers took advantage from the knowledge transfer between the participating universities (see Figure 3).

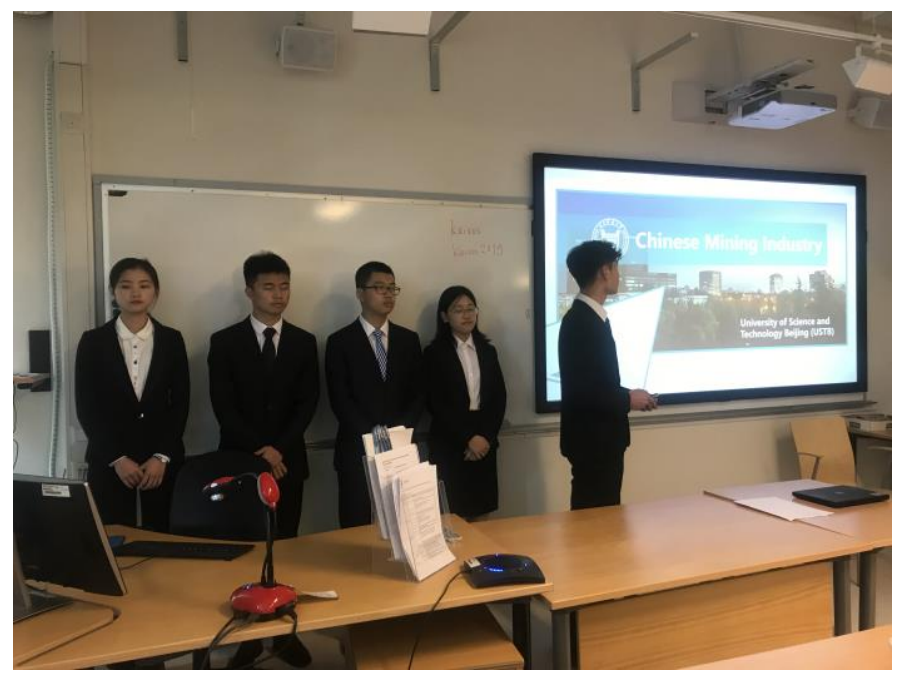

Figure 3: Students from USTB presenting Chinese Mining Industry.

\subsection{Adjustments during Pandemic 2020}

Travel restrictions prohibited the welcoming of exchange students to Finland, however a remote version of the Sustainable Mines course was held twice. Teaching platforms were moodle, zoom, and adobe connect. Quizzes were preformed with Kahoot and Moodle to deepen the understanding. Groupwork was performed in zoom break-out rooms, and moderated by professors and teaching assistants, as seen in Figure 4. Laboratory hands-on work was replaced by virtual laboratory work and videos and online-virtual tours. Laboratory exercises were followed by video, and the results given as spreadsheet for results calculation. Excursions were replaced by pictures and videos. 


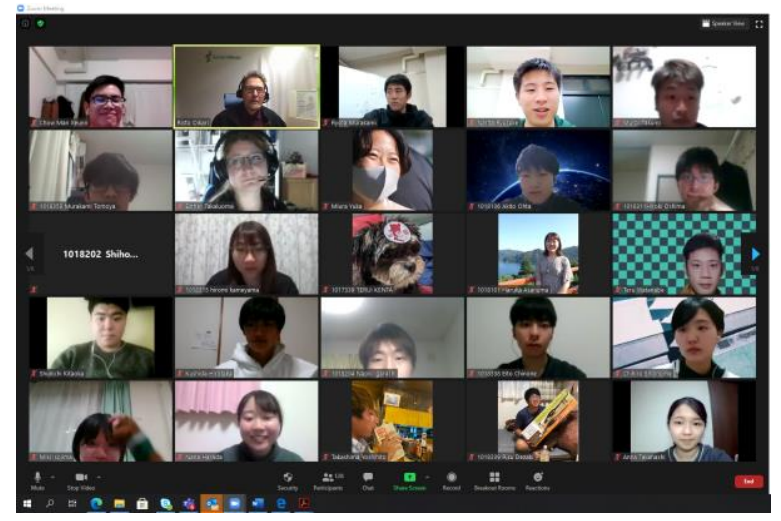

Figure 4: Screenshot of groupwork.

\subsection{Feedback 2020}

Though some applications stressed the streaming power from receiving and sending entity, the feedback was overwhelmingly positive. Virtual laboratory tours and laboratory exercises were praised, indicating the need of virtualizing hands-on work. Groupwork was moderated with the help of receiving institute, which helped keeping the discussion between students active. The possibility to interact between cultures was greatly reduced, some cultural and language studies were included into the syllibus.

\subsection{Teaching Mode Comparison between 2019 and 2020.}

The approximate time per teaching field in 2019 and 2020 is depicted in Figure 3. Naturally, the overall time spend on lectures was far higher than in 2019, as the amount of excursions was decreased. Laboratory courses were replaced 1:1 with virtual courses. Groupwork in online modus, was challenging, and therefore slightly shorter than for the live-course, however to keep the interest high, the involvement of stakeholders, the discussion of their role and impact was increased slightly. Cultural exchange possibilities were slight, and mainly concentrated to starting and ending ceremony.

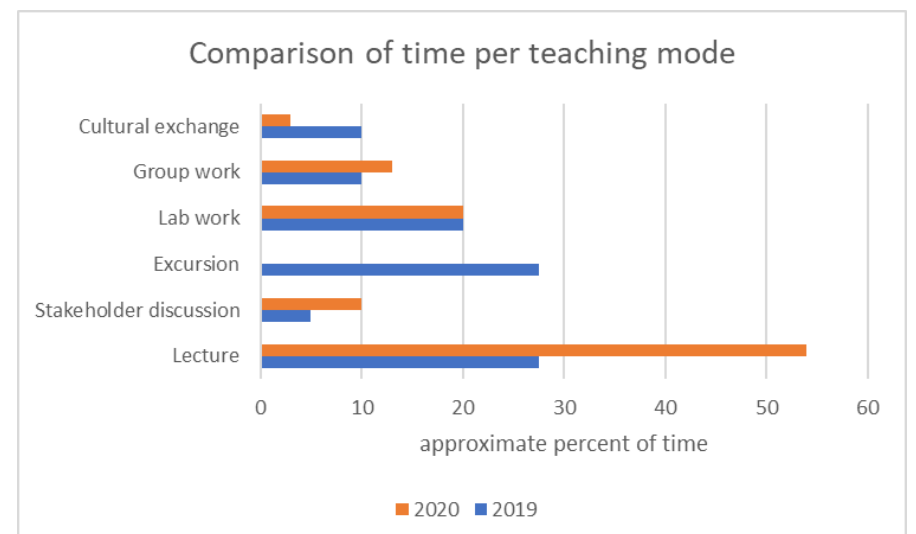

Fig. 3: Differences in time spend in each area of instructions, indicating the difference between 2019 and 2020 courses. 


\section{Discussion and Conclusions, Outlook}

The three Partners (Oulu University, Kajaani University of Applied Sciences, A. Peronius) continue to work together to improve and expand the Mining School on Sustainable Mining. The lockdown in many countries due to COVID-19 in 2020-21 made the need for virtual education evident to the world. While some excursion and virtual laboratory work obvious to the world. The pedagogical need for hands-on work in natural science is undisputed. KAMK is currently working on creating a VR-environmental for mining labs and on introducing virtual excursions. While this may not compare completely with the real experience, the positive effect is clear. More work to engage between the cultures in a remote course need to be explored, to reproduce the "summer school" feeling, which includes extensive stay in a foreign country and being exposed to new customs. While a live-version of sustainable mining course is preferred for optimal teaching and learning outcome, both on subject and as growing as a well rounded human, the piloting of the course concept has shown, that active interaction and discussion between different universities, stakeholders, and cultures is possible. In future new applications will be available to further improve the experience. KAMK and partners are continuously working on teaching the next generation of mining engineers in sustainable techniques and on how to exploite future mining projects, without affecting the sensitive arctic environment.

\section{References}

[1] P. Alves Dias, D. Blagoeva, C. Pavel, N. Arvanitidis, "Cobalt: demandsupply balances in the transition to electric mobility", EUR 29381 EN, Publications Office of the European Union, Luxembourg, 2018, doi:10.2760/97710.

[2]Stedman, Yunis, Aliakbari (2020): Fraser Institute Annual Survey of Mining Companies - 2019, Frazer institute. [online] Available: https://www.fraserinstitute.org/studies/annual-survey-of-mining-companies-2019. 